Check for updates

Cite this: RSC Adv., 2019, 9, 27883

Received 27th June 2019

Accepted 23rd August 2019

DOI: $10.1039 / c 9 r a 04864 b$

rsc.li/rsc-advances

\title{
Tandem grinding reactions involving aldol condensation and Michael addition in sequence for synthesis of 3,4,5-trisubstituted isoxazoles $\uparrow$
}

\author{
Xiao-Mu Hu, + $^{\mathrm{a}}$ Hai Dong, $\$^{\mathrm{b}}$ Yue-Dan Li, ${ }^{a}$ Ping Huang, ${ }^{a}$ Zhuang Tian ${ }^{a}$ \\ and Ping-An Wang (iD) *a
}

A one-pot, base-catalyzed, tandem grinding process involving carrying out aldol condensation and Michael addition in sequence to produce 3,4,5-trisubstituted isoxazoles from 3,5-dimethyl-4-nitroisoxazole, aromatic aldehydes and activated methylene compounds has been developed. In the presence of 10 mol\% of pyrrolidine, aldol condensations of 3,5-dimethyl-4-nitroisoxazole with various aromatic aldehydes were performed with 3-10 minutes of grinding to provide 5-styryl-3-methyl-4nitroisoxazoles in good to quantitative yields without further purification. Then, Michael additions between 5-styryl-3-methyl-4-nitroisoxazoles and activated methylene compounds (including ethyl 2nitroacetate and alkyl 2-cyanoacetates) were carried out in the presence of $10 \mathrm{~mol} \%$ of $\mathrm{Et}_{3} \mathrm{~N}$ in the same mortar with 3-5 minutes of continuous grinding to produce 3,4,5-trisubstituted isoxazoles in good to excellent yields.

\section{Introduction}

Maximizing the efficiency of reactants and reducing waste generation are important contributions to atomic economy and green chemistry. Many chemists have paid increasing attention to Michael addition for $\mathrm{C}-\mathrm{C}$ and $\mathrm{C}-$ heteroatom bond formation in recent years. ${ }^{1}$ Generally, the conventional Michael addition reactions are performed in solvent conditions, and some cases take a long reaction time (up to 7 days). In response to the requirements of green chemistry, scientists have been working on developing synthetic methods that generate little environmental pollution and display high atom economy. ${ }^{2}$ Therefore, the study of solvent-free Michael reactions involving microwave irradiation, ultrasonic irradiation and mechanochemical synthesis has also been reported extensively. ${ }^{3}$ On the one hand, reactions performed under solvent-free grinding conditions are very attractive to synthetic chemists because these reactions are easy to manipulate, cost little, and are highly efficient. The molecules in the solid state display large contact areas and high local concentration, which speeds up the reaction and increases selectivity. On the other hand, one-pot reactions ${ }^{4}$ are also highly

${ }^{a}$ Department of Medicinal Chemistry, School of Pharmacy, The Fourth Military Medical University, Changle Xilu 169, Xi'an, 710032, P. R. China

${ }^{b}$ College of Pharmacy, Xi'an Medical University, No. 1 Xinwang Rd, Weiyang Dist., Xi'an, 710021, P. R. China. E-mail: ping_an1718@outlook.com

$\dagger$ Electronic supplementary information (ESI) available. See DOI: 10.1039/c9ra04864b

¥ Co-first authors. These two authors have made the same level of contribution to this work. recommended by synthetic chemists because of their high modularity and simple manipulation. In this regard, the tandem grinding reaction is regarded as a quasi-one-pot reaction because all of its reaction steps are completed in the same mortar. Ideal solutions for the synthesis of active pharmaceutical ingredients and biological products, and new strategies to improve the atomic economy of important chemical processes and valuable structures are still in demand.

Nitrogen-containing heterocyclic compounds, especially isoxazole and its derivatives, are very important heterocyclic cores with a wide range of organic and bio-activities, and are present in many natural products and medicines (Fig. 1). $.^{5-7} 3-$ Methyl-4-nitro-5-styrylisoxazoles can be easily prepared from commercially available 3,5-dimethyl-4-nitroisoxazole and

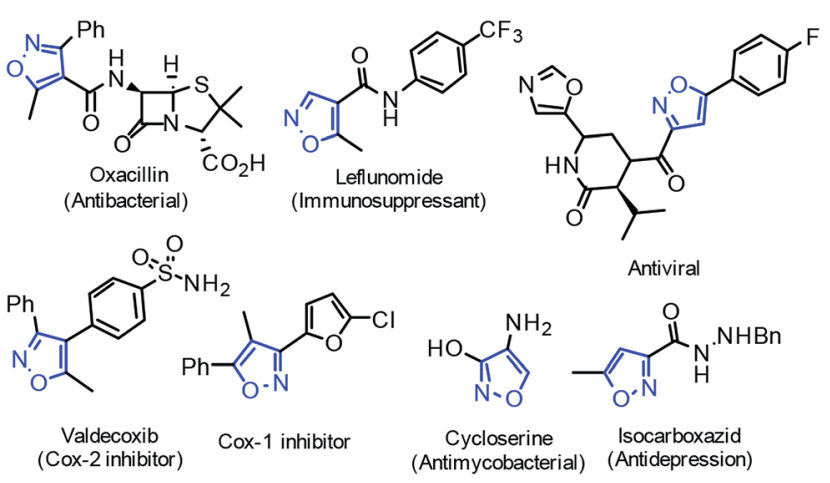

Fig. 1 Representative compounds containing the biologically active isoxazole core. 
aromatic aldehydes, and they are usually used as electrodeficient Michael acceptors for asymmetric catalytic Michael reactions with various activated methylene compounds such as isocyanoacetates, $\alpha, \beta$-unsaturated $\gamma$-butyrolactam, and anthrones. ${ }^{8}$ These Michael additions have all been performed under solvent conditions with relative long reaction times. Very recently, we reported a facile catalyst-free amination of $\beta$ nitrostyrenes and 2-aryl-3-nitro chromenes achieved by carrying out grinding. ${ }^{9}$ As part of our continuous efforts with grinding reactions, herein we demonstrated a facile synthetic route to 3,4,5-trisubstituted isoxazoles, in excellent yields, from 3,5dimethyl-4-nitroisoxazole, aromatic aldehydes and activated methylene compounds, achieved by performing aminecatalyzed tandem grinding (Fig. 2).

\section{Results and discussion}

\section{Pyrrolidine-catalyzed grinding reactions of aromatic aldehydes with 3,5-dimethyl-4-nitroisoxazole}

Aldol condensation is one of the important $\mathrm{C}-\mathrm{C}$ bond formation reactions in modern organic synthesis. Many enantioselective aldol reactions have been investigated extensively in the past two decades. Solvent-free aldol condensations have also been reported occasionally. In fact, the aldol condensation of aromatic aldehydes with 3,5-dimethyl-4-nitroisoxazole is usually reported to be carried out in a polar solvent system (e.g. EtOH) by using stoichiometric or catalytic amounts of organic secondary amines (such as diisopropyl amine, pyrrolidine, piperidine) under heating ( $2 \mathrm{~h}$ ) or room-temperature stirring for 8-12 h. ${ }^{10}$ We found that this reaction can be performed under solvent-free grinding conditions, and only take 3 to 10 minutes, greatly shortening the reaction time and providing a simple strategy for synthesizing 3-methyl-4-nitro-5-styrylisoxazoles (Scheme 1). Various aromatic aldehydes $(\mathbf{1 a}-\mathbf{q})$ were then used as substrates for such solvent-free grinding reactions to afford
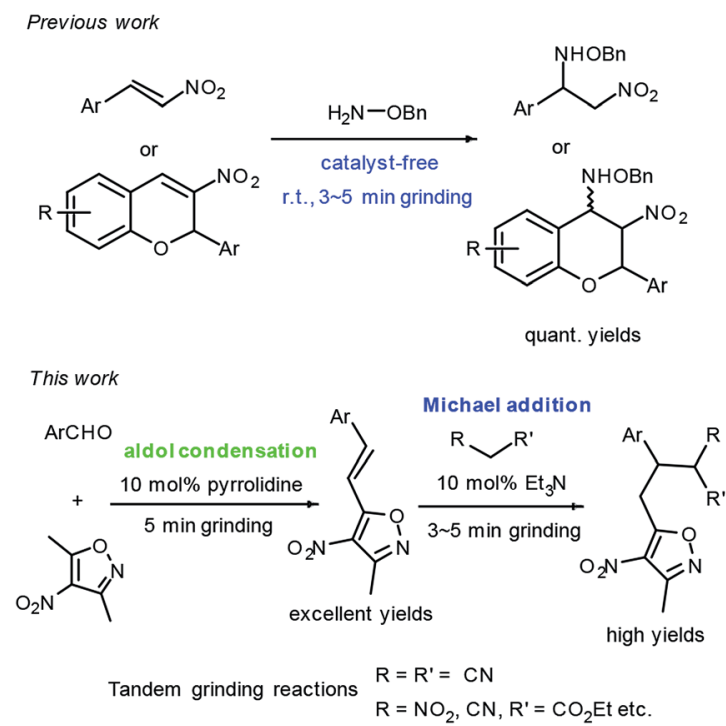

Fig. 2 The syntheses of 3,4,5-trisubstituted isoxazoles achieved by performing tandem grinding.

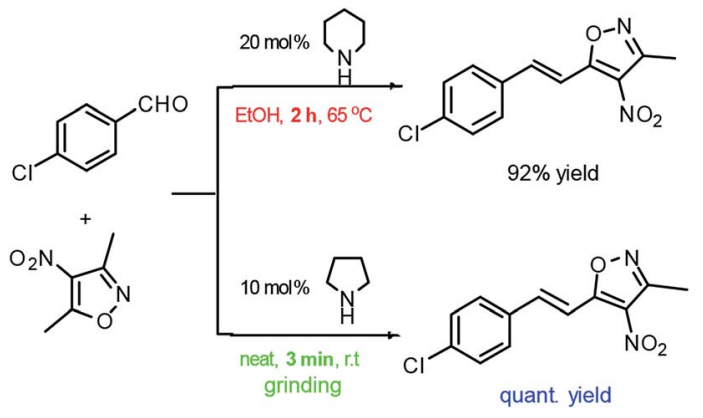

Scheme 1 The preparation of 3-methyl-4-nitro-5-styrylisoxazole carried out using solvent-free grinding.

3-methyl-4-nitro-5-styrylisoxazoles (2a-q) in good to quantitative yields. The reaction rates of aldehydes containing an electron-withdrawing group (EWG, aldehyde with $\mathrm{Cl}, \mathrm{Br}$ or $\mathrm{NO}_{2}$ ) were found to be higher than those with an electron-donating group (EDG, aldehyde with $\mathrm{OH}$ or $\mathrm{OMe}$ ). Aldehydes $\mathbf{1 i}, \mathbf{1 j}, \mathbf{1 k}$, $\mathbf{1 l}$ and $\mathbf{1 q}$ were made to react with nitroxazole to produce corresponding aldol condensation products $2 \mathbf{i}, 2 \mathbf{j}, 2 \mathbf{k}, 2 \mathbf{l}$ and $2 \mathbf{q}$ in quantitative yields by using $30 \mathrm{~mol} \%$ of pyrrolidine catalyst grinding at room temperature. All of the tested aldehydes provided aldol condensation products with 10 minutes of grinding, and the results are summarized in Fig. 3.

\section{Tandem grinding reactions involving aldol condensation and Michael addition in sequence for preparation of 3,4,5- trisubstituted isoxazoles}

Initially, the Michael reaction of 3-methyl-4-nitro-5styrylisoxazole $\mathbf{2 b}$ with ethyl 2-nitroacetate $\mathbf{3 a}$ was used as a model reaction to investigate the grinding Michael reaction. Various bases including $\mathrm{Na}_{2} \mathrm{CO}_{3}, \mathrm{~K}_{2} \mathrm{CO}_{3}, \mathrm{Et}_{3} \mathrm{~N},{ }^{\mathrm{i}} \mathrm{Pr}_{2} \mathrm{NEt}, N$ methylmorpholine (NMM), 1,8-diazabicyclo[5,4,0]undec-7-ene (DBU) and 1,4-diazabicyclo[2.2.2] octane (DABCO) were each used as a catalyst for this reaction. The results are shown in Scheme 2. Of these bases, the simple tertiary amine $\mathrm{Et}_{3} \mathrm{~N}$ was concluded to be the best choice for this Michael reaction because of its high efficiency, easy evaporation and convenient availability. For the first step to 3-methyl-4-nitro-5styrylisoxazoles, pyrrolidine was used as the catalyst, and for the second step to 3,4,5-trisubstituted isoxazole, $\mathrm{Et}_{3} \mathrm{~N}$ was used as the catalyst. We then considered the possibility of combining these two separate steps into one by developing a single catalyst containing both a secondary amine and tertiary amine in its structure. With this point in mind, we used $\mathbf{A 1}$ and $\mathbf{A 2}$ as catalysts, and performed a one-pot grinding reaction of 4-chlorobenzaldehyde 1b, 3,5-dimethyl-4-nitroisoxazole and ethyl 2nitroacetate 3a. The results are shown in Scheme 3. Both A1 and A2 were found to lead to complex results.

Afterwards, we used pyrrolidine as a catalyst for the first grinding reaction to prepare $\mathbf{2 b}$. When carrying out thin-layer chromatography (TLC) indicated that the starting materials $\mathbf{1 b}$ and 3,5-dimethyl-4-nitroisoxazole of this reaction were consumed, we then added ethyl 2-nitroacetate 3a and $10 \mathrm{~mol} \%$ $\mathrm{Et}_{3} \mathrm{~N}$ to the same mortar and performed another 3 minutes of 
<smiles>Cc1noc(/C=C/c2ccccc2)c1[N+](=O)[O-]</smiles>

2a

5 min grinding

quant yield<smiles>Cc1noc(/C=C/c2cccc(Br)c2)c1[N+](=O)[O-]</smiles>

$2 f$

3 min grinding

quant. yield<smiles>COc1ccc(/C=C/c2onc(C)c2[N+](=O)[O-])cc1</smiles>

$2 \mathrm{k}$

10 min grinding

$86 \%^{\mathrm{a}}$

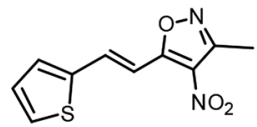

$2 p$

5 min grinding quant yield<smiles>Cc1noc(/C=C/c2ccc(Cl)cc2)c1[N+](=O)[O-]</smiles>

2b

3 min grinding

quant. yield<smiles>Cc1noc(/C=C/c2cccc(Cl)c2Cl)c1[N+](=O)[O-]</smiles>

2c

3 min grinding

quant. yield<smiles>Cc1noc(/C=C/c2ccc(Cl)cc2Cl)c1[N+](=O)[O-]</smiles>

2d

3 min grinding

quant. yield<smiles>Cc1noc(/C=C/c2cc(Cl)cc(Cl)c2)c1[N+](=O)[O-]</smiles>

quant. yield<smiles>Cc1noc(/C=C/c2ccc([N+](=O)[O-])cc2)c1[N+](=O)[O-]</smiles><smiles>Cc1noc(/C=C/c2cccc(O)c2)c1[N+](=O)[O-]</smiles>

2i

7 min grinding $86 \%^{a}$<smiles>COc1cc(/C=C/c2onc(C)c2[N+](=O)[O-])cc(OC)c1OC</smiles>

10 min grinding $80 \%^{\mathrm{a}}$

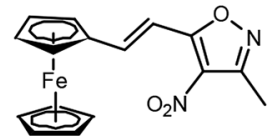

$2 q$

7 min grinding

$75 \%^{\mathrm{a}}$

5 min grinding

5 min grinding

quant. yield

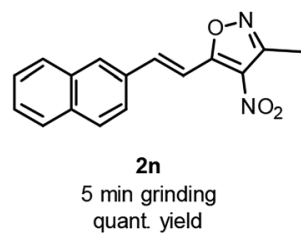<smiles>COc1cccc(/C=C/c2onc(C)c2[N+](=O)[O-])c1</smiles>

2j

10 min grinding

$85 \%^{a}$

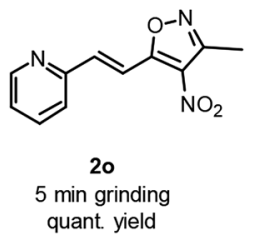

20

5 min grinding quant. yield

a. Due to the incompletion of reactions under standard conditions, $2 \mathbf{i}, \mathbf{2 j}, \mathbf{2 k}, \mathbf{2 l}$ and $\mathbf{2 q}$ were purified using flash column chromatography, and the yields of these products are based on the corresponding aldehydes. When the amount of pyrrolidine catalyst used was increased from $10 \mathrm{~mol} \%$ to $30 \mathrm{~mol} \%, \mathbf{2 i}, \mathbf{2} \mathbf{j}, \mathbf{2 k}, \mathbf{2 l}$ and $\mathbf{2 q}$ were obtained in quantitative yields, respectively.

Fig. 3 Pyrrolidine-catalyzed solvent-free grinding preparation of 3-methyl-4-nitro-5-styrylisoxazoles $2 \mathrm{a}-\mathrm{q}$ (1.0 mmol scale).

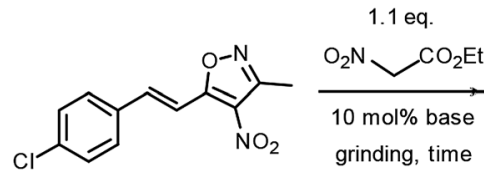

2b

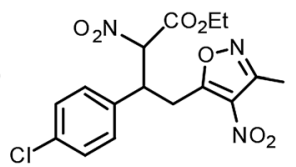

4ab

base: $\mathrm{Na}_{2} \mathrm{CO}_{3} \quad \mathrm{~K}_{2} \mathrm{CO}_{3} \quad \mathbf{E t}_{3} \mathbf{N} \quad \mathrm{PPh}_{3} \quad \mathrm{NMM} \quad \mathrm{EtNPr} r_{2} \quad$ DABCO DBU time: $5 \mathrm{~min} \quad 5 \mathrm{~min} \quad 3 \mathrm{~min} \quad 8 \mathrm{~min} \quad 5 \mathrm{~min} \quad 3 \mathrm{~min} \quad 3 \mathrm{~min} \quad 5 \mathrm{~min}$

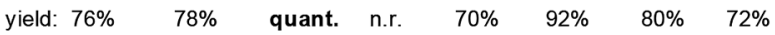

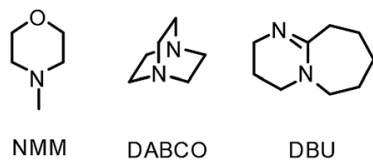

Scheme 2 The screening of bases for grinding preparation of 3,4,5trisubstituted isoxazole $4 a b$.

grinding at room temperature. In this way, $\mathbf{4 a b}$ was obtained in $92 \%$ yield. We called this strategy a tandem grinding reaction. By using this strategy, we performed aldol-Michael reactions of aromatic aldehydes 1 and 3,5-dimethyl-4-nitroisoxazole and activated methylene compounds including ethyl 2-nitroacetate, alkyl 2-cyanoacetates and malononitrile to provide 3,4,5trisubstituted isoxazoles 4 in good to excellent yields after a simple flash column chromatographic purification.

The results are shown in Fig. 4. When dialkyl malonates, ethyl acetoacetate and acetylacetone were used as Michael
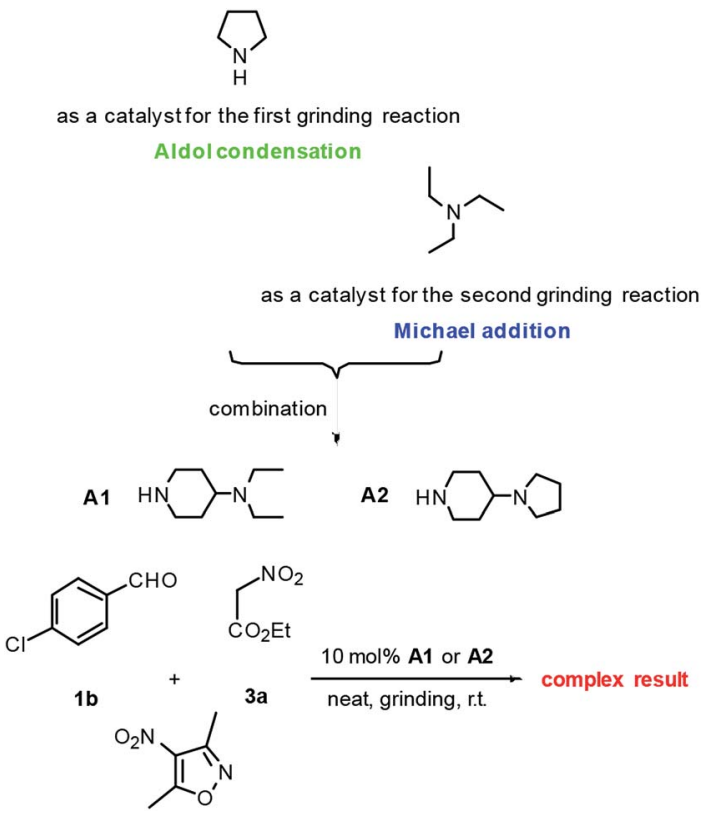

Scheme 3 The screening of catalysts $A 1$ and $A 2$ for one-pot grinding preparation of 3,4,5-trisubstituted isoxazole $4 \mathrm{ab}$.

donors, no corresponding product was formed under standard grinding conditions even with a prolongation of reaction time. All products were determined from their ${ }^{1} \mathrm{H}$ NMR spectra to be composed of diastereomers in a $1: 1$ ratio. 


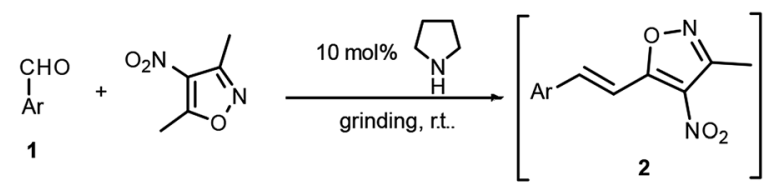

without separation for most case

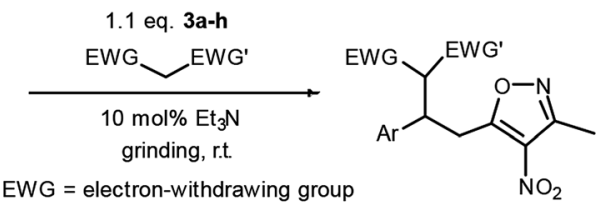

4 , various yields ${ }^{\mathrm{a}}$ a. Isolated yields of 4 based on aromatic aldehydes 1 .<smiles>CCOC(=O)C(C(Cc1onc(C)c1[N+](=O)[O-])c1ccccc1)[N+](=O)[O-]</smiles>

4aa, $89 \%$<smiles>CCOC(=O)C(Cc1onc(C)c1[N+](=O)[O-])C(Cc1ccc(Cl)cc1)[N+](=O)[O-]</smiles>

4ab, $93 \%$<smiles>CCOC(=O)C(Cc1onc(C)c1[N+](=O)[O-])C(Cc1cccc(Cl)c1Cl)[N+](=O)[O-]</smiles>

4ac, $91 \%$<smiles>CCOC(=O)C(Cc1onc(C)c1[N+](=O)[O-])C(Cc1ccc(Cl)cc1Cl)[N+](=O)[O-]</smiles>

4ad, $90 \%$<smiles>CCOC(=O)C(Cc1onc(C)c1[N+](=O)[O-])C(Cc1cc(Cl)cc(Cl)c1)[N+](=O)[O-]</smiles>

4ae, $91 \%$<smiles>CCOC(=O)C(Cc1onc(C)c1[N+](=O)[O-])C(Cc1onc(C)c1[N+](=O)[O-])C(Cc1onc(C)c1[N+](=O)[O-])C(Cc1ccc(Br)cc1)c1ccc(Br)cc1</smiles><smiles>CCOC(=O)C(Cc1onc(C)c1[N+](=O)[O-])C(Cc1cccc(O)c1)[N+](=O)[O-]</smiles>

4ai, $82 \%$<smiles>CCOC(=O)C(Cc1c(C)noc1[N+](=O)[O-])C(Cc1cccc(OC)c1)[N+](=O)[O-]</smiles>

4aj, $81 \%$<smiles>CCOC(=O)C(Cc1onc(C)c1[N+](=O)[O-])C(Cc1ccc(OC)cc1)[N+](=O)[O-]</smiles>

4ak, $85 \%$<smiles>COC(=O)C(Cc1onc(C)c1[N+](=O)[O-])C(Cc1cc(OC)c(OC)c(OC)c1)[N+](=O)[O-]</smiles>

4al, $81 \%$<smiles>CCOC(=O)C(Cc1onc(C)c1[N+](=O)[O-])C(Cc1cccc2ccccc12)[N+](=O)[O-]</smiles>

$4 \mathrm{am}, 88 \%$<smiles>CCOC(=O)C(Cc1onc(C)c1[N+](=O)[O-])C(Cc1ccc2ccccc2c1)C(=O)[O-]</smiles>

4an, $88 \%$<smiles>CCOC(=O)C(Cc1onc(C)c1[N+](=O)[O-])C(c1ccccn1)[N+](=O)[O-]</smiles>

4ao, $89 \%$<smiles>CCOC(=O)C(Cc1onc(C)c1[N+](=O)[O-])C(Cc1cccs1)[N+](=O)[O-]</smiles>

4ap, $87 \%$<smiles>C=CCOC(=O)C(C#N)C(Cc1onc(C)c1[N+](=O)[O-])c1ccc(Cl)cc1</smiles>

4bd, $88 \%$

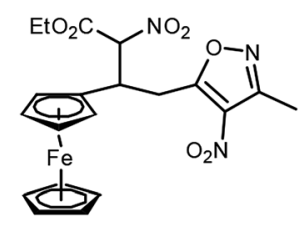

4aq, $72 \%$<smiles>CCOC(C#N)C(Cc1onc(C)c1[N+](=O)[O-])c1ccc(Cl)cc1</smiles>

4ba, $88 \%$<smiles>CCCOC(=O)C(C#N)C(Cc1onc(C)c1[N+](=O)[O-])c1ccc(Cl)cc1</smiles>

4bb, $85 \%$<smiles>Cc1noc(CC(c2ccc(Cl)cc2)C(C#N)C(=O)OCC(C)C)c1[N+](=O)[O-]</smiles>

$4 \mathrm{bc}, 82 \%$

Fig. 4 Tandem grinding reactions for the preparation of 3,4,5-trisubstituted isoxazoles (1.0 mmol scale).

\section{Experimental}

\section{General procedure for synthesis of compound 4}

To a dried agate mortar, aromatic aldehyde 1 (1 mmol), 3,5dimethyl-4-nitroisoxazole (white crystal, $0.15 \mathrm{~g}, 1.1 \mathrm{mmol}$ ) and pyrrolidine $(8 \mu \mathrm{L}, 0.1 \mathrm{mmol})$ were added successively. The mixture was subjected to grinding at room temperature for 3$5 \mathrm{~min}$, and the reaction was monitored using TLC (for most cases, the color of the reaction mixture changed obviously during the grinding process). When TLC indicated that aromatic aldehyde $\mathbf{1}$ was consumed, the activated methylene compound 3 (liquid, $1.2 \mathrm{mmol})$ and $\mathrm{Et}_{3} \mathrm{~N}(12 \mu \mathrm{L}, 0.1 \mathrm{mmol})$ were added, and grinding was carried out for another 3-5 min. (Note: aldehydes $\mathbf{1 i}, \mathbf{1} \mathbf{j}, \mathbf{1 k}, \mathbf{1} \mathbf{l}$ and $\mathbf{1 q}$ were not used up under standard conditions, so the corresponding aldol condensation products $\mathbf{2 i}, \mathbf{2 j}, \mathbf{2 k}, \mathbf{2 l}$ and $\mathbf{2 q}$ were separated from their respective unconsumed reactants by performing flash column chromatography.) TLC was used to check the reaction process. The crude product was diluted with DCM $(20 \mathrm{~mL})$ and the resulting solution was successively washed with $\mathrm{H}_{2} \mathrm{O}(5 \mathrm{~mL})$ and brine $(5$ $\mathrm{mL}$ ). The organic layers were dried over $\mathrm{Na}_{2} \mathrm{SO}_{4}$, filtered, and concentrated. The pure product $\mathbf{4}$ was obtained by carrying out 
flash column chromatography (eluted by petroleum ether/ethyl acetate $=10 / 1$ to $5 / 1, \mathrm{v} / \mathrm{v}$ ).

\section{Conclusions}

In conclusion, we have developed a tandem grinding strategy to prepare 3,4,5-trisubstituted isoxazoles from aromatic aldehydes, 3,5-dimethyl-4-nitroisoxazole and activated methylene compounds in the presence of catalytic amounts of pyrrolidine and $\mathrm{Et}_{3} \mathrm{~N}$ in high yields and efficiency. The transformations of these 3,4,5-trisubstituted isoxazoles to complex structures for investigation of their bio-activities are underway in our laboratory.

\section{Conflicts of interest}

There are no conflicts to declare.

\section{Acknowledgements}

We thank the National Science Foundation of China (no. 21372259) for financial support of this work.

\section{Notes and references}

1 (a) S.-M. Yang, P. Karanam, M. Wang, Y.-J. Jang, Y.-S. Yeh, P.-Y. Tseng, M. R. Ganapuram, Y.-C. Liou and W.-W. Lin, Chem. Commun., 2019, 55, 1398; (b) Y. Hayashi, T. Yamada, M. Sato, S. Watanabe, E. Kwon, K. Iwasaki and S. Umemiya, Org. Lett., 2019, 21, 5183; (c) Y. Hayashi, K. Nagai and S. Umemiya, Eur. J. Org. Chem., 2019, 678; (d) X. Zhang, T.-L. Wang, X.-J. Liu, X.-C. Wang and Z.-J. Quan, Org. Biomol. Chem., 2019, 17, 2379; (e) M. G. Vinogradov, O. V. Turova and S. G. Zlotin, Org. Biomol. Chem., 2019, 17, 3670; ( $f$ ) T. A. Hamlin, I. Fernández and F. M. Bickelhaupt, Angew. Chem., Int. Ed., 2019, 58, 8922; (g) C.-K. Tang, K.-X. Feng, A.-B. Xia, C. Li, Y.-Y. Zheng, Z.-Y. Xu and D.-Q. Xu, RSC Adv., 2018, 8, 3095; (h) S. Nayak, P. Panda, S. Bhakta, S. K. Mishra and S. Mohapatra, RSC Adv., 2016, 6, 96154; (i) B.-L. Zhao and D.-M. Du, Chem. Commun., 2016, 52, 6162.

2 (a) D. Heijnen, M. von Zuijlen, F. Tosia and B. L. Feringa, Org. Biomol. Chem., 2019, 17, 2315; (b) X.-T. Fang, Z.-H. Deng, W.-H. Zheng and J. C. Antilla, ACS Catal., 2019, 9, 1748; (c) C. H. Lam, V. Escande, K. E. Mellor, J. B. Zimmerman and P. T. Anastas, J. Chem. Educ., 2019, 96, 4761; (d) T. B. Nguyen and P. Retailleau, Org. Lett., 2017, 19, 3879; (e) R. A. Sheldon, Green Chem., 2016, 18, 3180.

3 (a) N. A. De Simone, S. Meninno, C. Talotta, C. Gaeta, P. Neri and A. Lattanzi, J. Org. Chem., 2018, 83, 10318; (b) M. Bláha, O. Trhlíková, J. Podešva, S. Abbrent, M. Steinhart, J. Dybal and M. Dušková-Smrčková, Tetrahedron, 2018, 74, 58; (c) C. G. Avila-Ortiz, L. Díaz-Corona, E. Jiménez-González and E. Juaristi, Molecules, 2017, 22, 1328; (d) E. Drège, J. Oko,
P.-E. Venot, N. Gigant and D. Joseph, $R S C A d v$., 2015, 5, 96720; (e) S. Guin, D. Majee, S. Biswas and S. Samanta, Asian J. Org. Chem., 2018, 7, 1810; (f) A. J. Beneto, J. Sivamani, V. Ashokkumar, R. Balasaravanan, K. Duraimurugana and A. Siva, New J. Chem., 2015, 39, 3098; (g) C. Wu, L.-H. Lu, A.-Z. Peng, G.-K. Jia, C. Peng, Z. Cao, Z.-L. Tang, W.-M. He and X.-H. Xu, Green Chem., 2018, 20, 3683; (h) J. Kaur, A. Kumari and S. S. Chimni, Tetrahedron, 2017, 73, 802; (i) M. Leonardi, M. Villacampa and J. C. Menéndez, Chem. Sci., 2018, 9, 2042; (j) T. K. r Achar, A. Bose and P. Mal, Beilstein J. Org. Chem., 2017, 13, 1907; (k) M. Tavakolian, S. Vahdati-Khajeh and S. Asgari, ChemCatChem, 2019, 11, 2943.

4 (a) T. Wang, X.-S. Qing, C.-L. Dai, Z.-J. Su and C.-D. Wang, Org. Biomol. Chem., 2018, 16, 2456; (b) Y. Hayashi, Chem. Sci., 2016, 7, 866; (c) S. K. Arepalli, B. Park, J.-K. Jung, K. Lee and H. Lee, Tetrahedron Lett., 2017, 58, 449; (d) S. Dochain, F. Vetica, R. Puttreddy, K. Rissanen and D. Enders, Angew. Chem., 2016, 128, 16387; (e) B.-C. Hong, A. RajaVishal and M. Sheth, Synthesis, 2015, 47, 3257; $(f)$ L. Zhen, K. Yuan, X.-Y. Li, C.-Y. Zhang, J. Yang, H. Fan and L.-Q. Jiang, Org. Lett., 2018, 20, 3109; (g) T. Bzeih, D. Lama, G. Frison, A. Hachem, N. Jaber, J. Bignon, P. Retailleau, M. Alami and A. Hamze, Org. Lett., 2017, 19, 4670.

5 (a) M. Baumann and I. R. Baxendale, Beilstein J. Org. Chem., 2013, 9, 2265; (b) M. Baumann, I. R. Baxendale, S. V. Ley and N. Nikbin, Beilstein J. Org. Chem., 2011, 7, 442.

6 (a) A. E. Garces and M. J. Stocks, J. Med. Chem., 2019, 62, 4815; (b) H. Zahra, R. Ali and R.-A. Nima, Curr. Org. Chem., 2018, 22, 2256.

7 (a) M. Börjesson, A. Tortajada and R. Martin, Chem, 2019, 5, 254; (b) Q. Zhao, C. Peng, H. Huang, S.-J. Liu, Y.-J. Zhong, W. Huang, G. He and B. Han, Chem. Commun., 2018, 54, 8359.

8 (a) S. Rout, H. Joshi and V. K. Singh, Org. Lett., 2018, 20, 2199; (b) B. Zhu, R. Lee, Y.-L. Yin, F.-Y. Li, M. Coote and Z.-Y. Jiang, Org. Lett., 2018, 20, 429; (c) F. Li, W.-L. Pei, J.-J. Wang, J. Liu, J. Wang, M.-L. Zhang, Z.-M. Chen and L.-T. Liu, Org. Chem. Front., 2018, 5, 1342; (d) M. F. A. Adamo, P. Disetti, M. Moccia, D. Salazar-Illera and S. Surisetti, Org. Biomol. Chem., 2015, 13, 10609; (e) B. Lin, W.-H. Zhang, D.-D. Wang, Y. Gong, Q.-D. Wei, X.-L. Liu, T.-T. Feng, Y. Zhou and W.-C. Yuan, Tetrahedron, 2017, 73, 5176; $(f)$ V. Sharma, J. Kaur and S. S. Chimni, Eur. J. Org. Chem., 2018, 3489; (g) X.-L. Liu, W.-Y. Han, X.-M. Zhang and W.-C. Yuan, Org. Lett., 2013, 15, 1246.

9 D.-X. Cui, Y.-D. Li, J.-C. Zhu, Y.-Y. Jia, A.-D. Wen and P.-A. Wang, Curr. Org. Synth., 2019, 16, 449.

10 (a) M. F. A. Adamo, E. F. Duffy, D. Donati and P. SartiFantoni, Tetrahedron, 2007, 63, 2047; (b) J.-L. Zhang, X.-H. Liu, X.-J. Ma and R. Wang, Chem. Commun., 2013, 49, 9329. 